Lý do vào viện do đại tiện nhày máu $(82,57 \%)$ chiếm chủ yếu. Thời gian trung bình phát hiện bệnh là $3,72 \pm 4,20$ (tháng), chủ yếu bệnh nhân phát hiện bệnh sớm trong 3 tháng đầu chiếm $66,06 \%$. Triệu chứng lâm sàng đại tiện nhày máu chiếm $90,83 \%$, gây sút cân chiếm $39,45 \%$.

Tổn thương đại thể giảii phẫu bệnh dạng loét sùi $(40,37 \%)$, vi thể UTBM tuyến $(87,16 \%)$ chiếm chủ yếu, phần lớn UTTT có độ biệt hóa vừa $(83,49 \%)$. Đa số chưa có di căn hạch vùng với 65 BN (59,63\%). Mức độ xâm lấn u ở giai đoạn T3 chiếm tỷ lệ chủ yếu (68,80\%).

\section{TÀI LIÊU THAM KHẢO}

1. Trần Anh Cường (2017), Nghiên cứu đăc điểm di căn hạch và kêt quả điều trị phẫu thuật ung thq trực tràng tại bệnh viện K, Luận án Tiến sĩ, Đại học Y Hà Nội.

2. Mai Đình Điểu (2014), Nghiên cứu ứng dung phâu thuât nội soi trong điêu trị ung thư trực tràng, Luận án Tiến sĩ, Đại học Y dược Huế.
3. Quách Văn Kiên (2019), Nghiên cứu ứng dụng phẩu thuâat nôi soi bảo tồn cơ thắt trong ung thư trực tràng giữa và dưới, Luận án Tiến sĩ, Đại học Y Hà̀ nội.

4. Phạm Cẩm Phương (2013), Nghiên cứu hiệu quả của hóa xạ trị tiên phẩu trong điêu trị bệnh ung thư trực tràng giai đoạn xâm lấn, Luận án Tiển sỹ Y học, Trường Đại học Y Hà Nội.

5. Lê Quốc Tuấn (2020), Đánh giá kết quả phẫu thuật cắt đoan và nối máy trong điều trị ung thư trực tràng giữa và thấp, Luận án Tiến sĩ y học, Trường đại học $Y$ Hà Nội.

6. Freddie Bray, Jacques Ferlay, Isabelle Soerjomataram, et al. Global Cancer Statistics 2018: GLOBOCAN Estimates of Incidence and Mortality Worldwide for 36 Cancers in 185 Countries. Ca Cancer J Clin (2018); 68: 394-424.

7. American Joint Committee On Cancer. AJCC Cancer Staging Manual Seventh Edition (2010): $143-164$.

8. Jin C. Kim, Chang S. Yu, Seok-B Lim, et al. Outcomes of ultra-low anterior resection combined with or without intersphincteric resection in lower rectal cancer patients. Int J Colorectal Dis (2015): $1-11$.

\title{
CẢM GIÁC ĐAU SAU SỬA SOẠN ỐNG TUỶ BẰNG PHƯƠNG PHÁP QUAY LIÊN TƯC VÀ QUAY QUA LAI
}

\section{TÓM TẮT.}

Muc tiêu: Mục tiêu nghiên cứu là đánh giá cảm giác đau sau sửa soạn ống tuỷ bằng phương pháp dùng trâm máy quay liên tục và quay qua lại. Đối tượng và phương pháp: Thử nghiệm lâm sàng với hai nhóm nghiên cứu sửa soạn ống tử bằng phương pháp quay liên tục (ProTaper Next) và quay qua lại (WaveOne Gold) trên 36 răng có chỉ định nội nha ở các bệnh nhân trên 18 tuổi. Đánh giá cảm giác đau trước và sau sửa soạn 1, 2, 7 ngày với bảng câu hỏi và khám lâm sàng. Kết quả: Cảm giác đau trước điều trị, sau sửa soạn 1, 2, 7 ngày giữa hai nhóm quay liên tục và quay qua lại đều khác biệt không có ý nghĩa thống kê. Tình trạng gõ đau trước và sau sửa soạn 7 ngày của hai nhóm cũng khác biệt không có ý nghĩa thống kê. Kết luận: Phương pháp quay liên tục và quay qua lại có hiệu quả tương tự nhau trong việc giảm đau sau sửa soạn ống tuỷ 7 ngày.

Tư khóa: Đau, quay liên tục, quay qua lại, WaveOne Gold, ProTaper Next.

\section{SUMMARY}

\section{PAIN RESPONSE AFTER}

* Đai hoc Y Dượ TP. Hồ Chí Minh

Chịu trách nhiệm chính: Nguyễn Ngọc Phúc

Email: nguyenngocphucdds@gmail.com

Ngày nhận bài: 11/5/2021

Ngày phản biên khoa học: 29/5/2021

Ngày duyệt bài: 21/6/2021/

\section{Nguyễn Ngọc Phúc*, Phạm Văn Khoa* ENDODONTICPREPARATION BY ROTARY AND RECIPROCATING METHODS}

Objectives: The aim of study was to evaluate ofpain response after endodontic preparation by rotary and reciprocating methods. Subjects and methods: A clinical trial with two groups were prepared by rotary andreciprocatingfile systems (ProTaper Nextand WaveOne Gold) on 36 teeth with endondontic indication in patiens over 18 years old. Pain response was assessed before and after preparation 1,2,7 days with questionnaires and clinical examination. Results: Pain responsebetween two groups of rotary and reciprocating methods was not statistically significant difference before andafter preparation $1,2,7$ days. Pain response when percusionoftwo groups was also not statistically significant difference before and afterpreparation 7 days. Conclusion: Rotaryand reciprocatingmethods were similarly effective in reducing pain after 7 days of endodonticpreparation.

Key words: Pain, rotary, reciprocating, WaveOne Gold, ProTaper Next.

\section{I. ĐẶT VẤN ĐỀ}

Đau sau điêu trị nội nha nói chung và đau sau sửa soạn ống tuỷ nói riêng là một trong những tiêu chí rất quan trọng để đánh giá sự thành công của điều trị. Đau sau điêu trị nội nha có thể xảy ra trong vài giờ hoặc vài ngày sau khi điều trị. Mức độ đau cao nhất được ghi nhận 
trong giai đoạn đầu sau điều trị nội nha lên đến 12 giờ, điều này có thể là do quá trình viêm đang diễn ra. Mức độ phổ biến và mức độ nghiêm trọng của cơn đau giảm đáng kể trong vòng 48 giờ đầu tiên [1].

Mặc dù có rất nhiều nghiên cứu về chủ đề này, cơ chế của đau sau điều trị nội nha vẫn chưa rõ ràng. Nguyên nhân thường được cho là một quá trình đa yếu tố phức tạp bị ảnh hưởng bởi giới tính (đau sau nội nha được báo cáo ở nữ giới nhiều hơn nam giới), bệnh lý tuỷ và mô quanh chóp, loại răng, vùng liên quan xoang hàm, sưngđau trước nội nha, đangđiêu trị bằng steroid toàn thân vì bệnh lý khácvà số lần hẹn [2]. Đau sau nội nha cũng có thể xảy ra do sửa soạn không đủ, dung dịch bơm rửa quá chóp, đẩy mùn ngà ra khỏi chóp, chấn thương khớp cắn, sót ống tủy. Do đó, việc lựa chọn loại trâm và phương pháp để sửa soạn ống tuỷ đóng một vai trò rất quan trọng. Sự đẩy các mùn ngà nhiễm trùng ra khỏi chóp trong quá trình sửa soạn ống tủy có thể làm trầm trọng thêm phản ứng viêm và gây ra cơn bùng phát viêm quanh chóp.

Trâm quay Nickel-Titanium (NiTi) đã được chứng minh là đẩy ít mùn ngà ra khỏi chóp hớn so với trâm tay bằng thép không gỉ [3]. Gần đây, nhiều thế hê trâm NiTi quay qua lại và quay liên tục đã được giới thiệu. Theo các nghiên cứu, cả hai hệ thổng trâm quay qua lại và trâm quay liên tục đều đạt được hiệu quả tương tự về việc giảm đôc tính và vi khuẩn nuôi cãy từ các ống tủy nhiểm trùng [4]. Để đánh giá tình trạng đau sau điêuu trị nội nha, hai bài phân tích tổng hợp của Hou và cộng sự (2017) và Martins và cộng sự (2019) đã đưa ra hai kết luận trái ngược nhau. Trong khi đó Martins và cộng sự [5] kết luận kết quả hoàn toàn ngược lại. Chính vì sự không nhất quát của các nghiên cứu này, kết hợp với những tiến bộ không ngừng trong công nghệ chế tạo trâm, nên chúng tôi thực hiện nghiên cứu này nhằm so sánh tình trạng đau giữa hai nhóm trâm quay qua lại và quay liên tục trên bệnh nhân và trong điều kiện thực tiễn tại Việt Nam.

\section{II. ĐỐI TƯợNG VÀ PHƯƠNG PHÁP NGHIÊN CỨU}

2.1. Thiết kế nghiên cứu: Thử nghiệm lâm sàng ngẫu nhiênvới hai nhóm nghiên cứusửa soạn ống tuỷ bằng hệ thống trâm quay qua lại (WaveOne Gold, Dentsply Sirona, Salzburg, Austria) và trâm quay liên tục (ProTaper Next, Dentsply Sirona, Salzburg, Austria).

2.2. Đối tượng nghiên cứu: Bệnh nhân trên 18 tuổi, điều trị tại Khoa Răng Hàm Mặt,Đại học Y Dược thành phố TP. Hồ Chí Minh (TPHCM)

2.3. Thời gian nghiên cứu: từ tháng 4/2020 - tháng4/2021.

2.4. Cõ̃ mấu và chon mẫu:Mẫu nghiên cứu là 36 răng có chỉ định điều trị nội nha, mối nhóm 18 răng. Sử dụng phương pháp bốc thăm ngẫu nhiên để chọn vào một trong hai nhóm nghiên cứu.

Tiêu chuẩn chọn mẩu: - Răng có chỉ định nội nha, chưa từng nội nha trước đây

- Bệnh nhân trên 18 tuổi, đủ sức khỏe để chữa rằng.

- Bệnh nhân chưa dùng thuốc giảm đau trước điều trị trong vòng $24 \mathrm{~h}$

- Răng không bị nứt dọc, chân dị dạng, ống tủy canxi hóa.

- Răng không có túi nha chu $>3$ mm, không lung lay

2.5. Phương pháp nghiên cứu và thu thâp số liệu: Khi đã thỏa các tiêu chí chọn mấu, bênh nhân sẽ được giải thích quá trình nghiên cứu, mời tham gia và ký phiếu chấp thuận đồng ý tham gia nghiên cứu. Sau đó, bệnh nhân sẽ được thu thập thông tin trước điều trị bằng cách:

- Ghi nhận trên phiếu khám ban đầu thông tin hành chính của bệnh nhân, hỏi lý do đến khám, bệnh sử.

- Mối bênh nhân được phát phiếu để đánh dấu mức độ đau trên thang VAS $10 \mathrm{~cm}$

- Khám lâm sàng, sử dụng đầu cán gương gõ trên mặt nhai, mặt ngoài, mặt trong của răng thử nghiêm. Khi gõ dùng sức vừa đủ để bênh nhân phân biệt được răng lành mạnh và răng bị viêm dây chằng.

Sau khi thu thập thông tin, tất cả bệnh nhân đều được điều trị bởi Bác sĩ chuyên gia nôi nha, thực hiện các bước đặt đê, mở tủy, đo chiều dài làm việc như quy trình thông thường tại khu lâm sàng. Khi bước vào giai đoạn sửa soạn ống tủy, bênh nhân được chia thành 2 nhóm bằng phương pháp rút thăm ngẫu nhiên không hoàn lại: nhóm sửa soạn bằng phương pháp quay liên tục (ProTaper Next) và nhóm sửa soạn bằng phương pháp quay qua lai (WaveOne Goid).

Quy trình sửa soạn ổng tuỷ ở 2 nhóm: Bơm rửa ống tủy bằng $\mathrm{NaOCl} 2,5 \%$. Dùng trâm K-file số 10 đi xuống hết chiều dài làm việc. Bơm EDTA gel vào miệng ống tủy để bôi trớn. Trên máy nội nha đặt chế độ tùy chọn. Đưa các trâm tạo đường trượt đến hết chiều dài làm việc (tốc độ 250 vòng/phút, mô men xoắn $2 \mathrm{Ncm}$ ). Sau đó, đưa trâm quay liên tục (lần lượt các trâm ProTaper Next - máy nội nha đặt chế độ quay liên tục tốc độ 300 vòng/phút, mồ men xoắn 2,5 
Ncm) hoặc trâm quay qua lại (một trâm WaveOne Gold duy nhất - máy nội nha đặt chế độ quay qua lại) đến hết chiều dài làm việc. Động tác đưa trâm xuống nhe nhàng không áp lực, nếu cảm giác bi chăt thì rút nhe trâm lên rồi sau đó mới đưa xuống tiếp. Sau mỗi lần thay dụng cụ, bơm rửa bằng $\mathrm{NaOCl} 2,5 \%$, lau sạch các rãnh trâm bằng gạc ẩm. Bơm rửa $2 \mathrm{ml} \mathrm{NaOCl}$ $2,5 \%$ sau khi sửa soạn hoàn tất.

Sau đó, tất cả các răng đều được quay $\mathrm{Ca}(\mathrm{OH})_{2}$ vào ống tủy và trám tạm, hẹ tái khám sau 7 ngày. Bệnh nhân sẽ được phát phiếu để ghi nhận mức độ đau theo thang VAS vào ngày thứ 1 , thứ 2 , thứ 7 sau sửa soạn. Các phiếu này sẽ được thu lại vào ngày thứ 7 khi bệnh nhân tái khám. Thuốc giảm đau Ibuprofen $400 \mathrm{mg}$ chỉ được sử dụng khi bệnh nhân không thể chịu đựng được cơn đau. Bệnh nhân được yêu câuu gọi vào số điện thoại khẩn khi đau không thể chịu đựng, được ghi nhận mức độ đau, hướng dẫn tái khám và sử dụng thuốc.

Sau sửa soạn 7 ngày, bệnh nhân đến tái khám, trả lại phiếu ghi nhận mức độ đau và được khám lâm sàng để đánh giá tình trạng đau khi gõ. Sau khi khám và ghi nhận, quy trình điều trị được tiếp tục thực hiện như thông thường tại khu lầm sàng Khoa Răng Hàm Mặt. Nếu ống tủy có thể thấm khô và không còn các triệu chứng lâm sàng, thực hiện trám bít với kỹ thuật 1 côn và xi măng trám bít AH26. Ngược lại, bệnh nhân sẽ được điêu trị thêm nhiêu lần hẹn tiếp theo cho đển khi có thể trám bít ống tuỷ và trám phục hồi phần thân răng.

2.6. Phân tích và xử lý thống kê. Các số liệu nghiên cứu thu thập từ bảng câu hỏi và khám lâm sàng được nhập vào Microsoft Excel và xử lý bằng phần mềm SPSS 20.0.

\subsection{Vấn đề y đức}

- Mẫu là những người tình nguyện tham gia nghiên cứu, được nghiên cứu viên giải thích trực tiếp về quy trình điều trị, lợi ích, nguy cơ, biến chứng có thể gặp của phương pháp điều trị.

-Kết quả nghiên cứu nhằm phục vụ cho mục đích y học, không nhằm mục đích khác.

-Nghiên cứu đã được Hội đồng đạo đức trong nghiên cứu y sinh trường Đại học Y dược TPHCM thông qua ngày 21/04/2020.

\section{KẾT QUẢ NGHIÊN CỨU VÀ BÀN LUÂN}

So sánh tình trạng đau sau điều trị nội nha giữa phương pháp quay liên tục và quay qua lại đã được nhiều nghiên cứu trên thế giới thực hiện, thậm chí đã có các bài tổng quan hệ thống và phân tích tổng hợp về chủ đề này. Tuy nhiên kết quả thu được giữa các báo cáo lại không đạt được sự đồng nhất, vì vậy việc đánh giá tình trạng đau giữa hai phương pháp này vẫn cần phải được tiếp tục nghiên cứu. Nghiên cứu của chúng tôi sử dụng thang đo VAS từ 0 (không đau) đến $10 \mathrm{~cm}$ (đau không chịu nổi) để đánh giá tình trạng đau trước và sau sửa soạn ống tủy 1 , 2, 7 ngày. Ngoài ra, tình trạng đau khi gõ cũng được đánh giá trên lâm sàng.

Mức độ đau trước điều trị giữa hai nhóm quay liên tục vào quay qua lại khác biệt không có ý nghĩa $(2,09 \pm 0,68$ và $1,69 \pm 0,68)$. Tình trạng đau sau sửa soạn ống tủy $1,2,7$ ngày của hai nhóm cũng khác biệt không có ý nghĩa. Trên đồ thị biểu hiện mức độ đau trung bình tại các thời điểm, xu hướng của cả hai nhóm là đều làm giảm đau từ trước điều trị đếnsau sửa soạn ống tuỷ 7 ngày. Tuy nhiên, nhóm quay qua lại gây đau nhiều hơn vào ngày thứ hai sau sửa soạn, nhưng sự khác biệt không có ý nghĩa $(p=0,309)$. Vào ngày thứ bảy sau sửa soạn, mức độ đau của cả hai nhóm đều thấp $(0,19 \pm 0,11$ và $0,14 \pm$ $0,11)$, gợi ý đây là thời điểm thích hợp để thực hiện trám bít ống tuỷ. Về tình trạng gõ đau trển lâm sàng, cả hai nhóm đều làm giảm đau từ trước điều trị đến ngày thứ 7 sau sửa soạn, sự khác biệt giữa hai nhóm không có ý nghĩa thống kê (bảng 2).

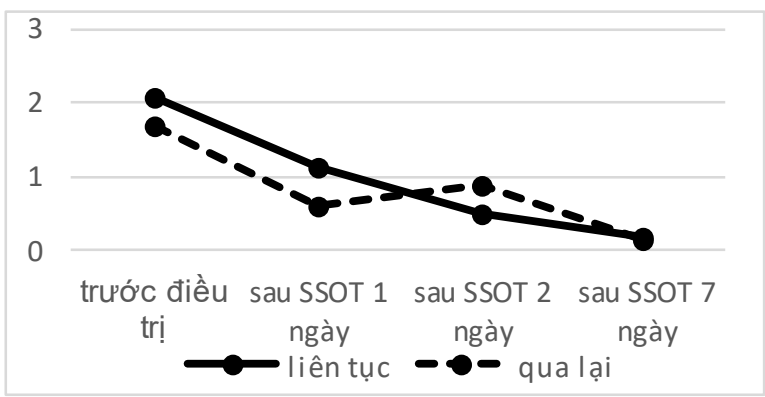

Biểu đồ 1. Mức độ đau trung binh tại các thời điểm.

Bảng 1. Múc độ đau theo thang VAS tại các thời điểm

\begin{tabular}{|c|c|c|c|}
\hline Nhóm & $\begin{array}{c}\text { Quay liên } \\
\text { tục } \\
\text { Thời điểm } \\
\text { (TB } \pm \text { ĐLC) }\end{array}$ & $\begin{array}{c}\text { Quay qua lại } \\
\text { (TB } \pm \text { ĐLC) }\end{array}$ & P* \\
\hline $\begin{array}{c}\text { Trước điều } \\
\text { trị }\end{array}$ & $2,09 \pm 0,68$ & $1,69 \pm 0,68$ & 0,462 \\
\hline $\begin{array}{c}\text { Sau SSOT 1 } \\
\text { ngày }\end{array}$ & $1,14 \pm 0,39$ & $0,59 \pm 0,37$ & 0,078 \\
\hline $\begin{array}{c}\text { Sau SSOT 2 } \\
\text { ngày }\end{array}$ & $0,49 \pm 0,22$ & $0,88 \pm 0,59$ & 0,309 \\
\hline $\begin{array}{c}\text { Sau SSOT 7 } \\
\text { ngày }\end{array}$ & $0,19 \pm 0,11$ & $0,14 \pm 0,11$ & 0,421 \\
\hline
\end{tabular}

SSOT: sửa soạn ống tuỷ

*: Phép kiểm Mann Whitney U 
Bảng 2. Ti lệ gõ đau trên lâm sàng

\begin{tabular}{|c|c|c|c|}
\hline Nhó̀m & $\begin{array}{c}\text { Quay liên } \\
\text { tục(n=18) }\end{array}$ & $\begin{array}{c}\text { Quay qua lại } \\
(\mathbf{n = 1 8})\end{array}$ & P* \\
\hline $\begin{array}{c}\text { Thớ điếm } \\
\text { Trước điêu } \\
\text { trị }\end{array}$ & $9(50 \%)$ & $8(44,4 \%)$ & 0,738 \\
\hline $\begin{array}{c}\text { Sau SSOT 7 } \\
\text { ngày }\end{array}$ & $3(16,7 \%)$ & $2(11,1 \%)$ & 0,630 \\
\hline
\end{tabular}

SSOT: sửa soạn ống tuỷ

*: phép kiểm chi bình phương

Như vậy, nhóm quay liên tục vào quay qua lại đều làm giảm đau theo thang VAS và giảm đau khi gõ sau sửa soạn ống tủy 7 ngày. Sự khác biệt giữa hai nhóm không có ý nghĩa thống kê. Tuy nhiên, nhóm quay qua lại gây khó chịu hơn cho bệnh nhân vào ngày thứ 2 sau sửa soạn. Kết quả này phù hợp với nhiều nghiên cứu trên thế giới, như của Cicek và cộng sự (2017) [6]. Tác giả Nekoofar và cộng sự (2015) cũng kêt luận rằng đau sau điều trị kéo dài và nhiêu hơn ở nhóm quay qua lại so với quay liên tục, tuy nhiên sự khác biệt không có ý nghĩa thống kề [7].

Nguyên nhân của đau sau điều trị nội nha thường được cho là một quá trình đa yếu tố phức tạp bị ảnh hưởng bởi giới tính (đau sau nội nha được báo cáo ở nữ giới nhiều hơn nam giới), bệnh lý tuỷ và mô quanh chóp, loại răng, vùng liền quan xoang hàm, sung đau trước nội nha, đang điều trị bằng steroid toàn thân vì bệnh lý khác và số lần hẹn. Đau sau nội nha cũng có thể xảy ra do sửa soạn không đủ, dung dịch bơm rửa quá chóp, đẩy mùn ngà ra khỏi chóp, chấn thương khớp cắn, sót ống tủy. Do đó, việc lựa chọn phương pháp sửa soạn ống tuỷ đóng một vai trò rất quan trọng. Sự đẩy các mùn ngà nhiễm trùng ra khỏi chóp trong quá trình sửa soạn ống tủy có thể làm trầm trọng thêm phản ứng viêm và gây ra cơn bùng phát viêm quanh chóp. Các yếu tố như quy trình bơm rửa, kích thước chóp sau cùng, thời gian sửa soạn ống tủy, kỹ thuật sửa soạn và thiết kế dụng cự có thể ảnh hưởng đến việc đẩy mùn ngà ra khỏi chóp. Một bài tổng quan hệ thống và phân tích tổng hợp của Caviedes-Bucheli và cộng sự năm 2015 đã đánh giá ảnh hưởng của các chế độ quay qua lại và quay liên tục đối với việc đẩy mùn ngà ra khỏi chóp và mối liên hệ sinh học với bệnh lý viêm quanh chóp có triệu chứng [8]. Họ kểt luận rằng cả hai chế độquay qua lại và liên tục đều đẩy mùn ngà khỏi chóp và biểu hiện bằng các kích thích đau. Các nghiên cứu được đánh giá bao gồm các nghiên cứu lâm sàng vài vitro, ủng hộ quan điểm là phản ứng viêm không bị ảnh hưởng bởi số lượng trâm mà bởi chế độ quay và thiết kế dụng cụ.
Tuy nhiên, điểm hạn chế của nghiên cứu này là chỉ đánh giá tình trạng đau sau sửa soạn ống tủy 7 ngày. Vì vậy, cần có các nghiên cứu khác để đánh giá tình trạng đau sau trám bít ống tuỷ và theo dõi điều trị lâu hơn nữa, nhằm đánh giá một cách hệ thống về sự thành công của điều trị nội nha trên cả lâm sàng và cận lâm sàng.

\section{KẾT LUÂ̂N}

Cả hai phương pháp quay qua lại vào quay liên tục đều làm giảm đau sau sửa soạn ống tuỷ 7 ngày. Sự khác biệt giữa hai phương pháp này không có ý nghĩa thống kê.

\section{TÀI LIẸU THAM KHẢO}

1. Cicek E, Kocak MM, Kocak S, Saglam BC, Turker SA (2017), "Postoperative pain intensity after using different instrumentation techniques: a randomized clinical study", J Appl Oral Sci, 25 (1), pp.20-6.

2. Wang C, Xu P, Ren L, Dong G, Ye L (2010), "Comparison of post-obturation pain experience following one-visit and two-visit root canal treatment on teeth with vital pulps: a randomized controlled trial", Int Endod J, 43 (8), pp.692-7.

3. Hou $X M$, Su $Z$, Hou BX (2017), "Post endodontic pain following single-visit root canal preparation with rotary vs reciprocating instruments: a meta-analysis of randomized clinical trials", BMC Oral Health, 17 (1), pp.86.

4. Martinho FC, Gomes AP, Fernandes AM, Ferreira NS, Endo MS, Freitas LF, et al. (2014), "Clinical comparison of the effectiveness of single-file reciprocating systems and rotary systems for removal of endotoxins and cultivable bacteria from primarily infected root canals", ] Endod, 40 (5), pp.625-9.

5. Martins CM, De Souza Batista VE, Andolfatto Souza AC, Andrada AC, Mori GG, Gomes Filho JE (2019), "Reciprocating kinematics leads to lower incidences of postoperative pain than rotary kinematics after endodontic treatment: A systematic review and meta-analysis of randomized controlled trial", J Conserv Dent, 22 (4), pp.320-31.

6. Cicek $E$, Kocak MM, Kocak S, Saglam BC, Turker SA (2017), "Postoperative pain intensity after using different instrumentation techniques: a randomized clinical study", J Appl Oral Sci, 25 (1), pp.20-6.

7. Nekoofar MH, Sheykhrezae MS, Meraji N, Jamee A, Shirvani A, Jamee J, et al. (2015), "Comparison of the effect of root canal preparation by using WaveOne and ProTaper on postoperative pain: a randomized clinical trial", J Endod, 41 (5), pp.575-8.

8. Caviedes-Bucheli J, Castellanos F, Vasquez N, Ulate E, Munoz HR (2016), "The influence of two reciprocating single-file and two rotary-file systems on the apical extrusion of debris and its biological relationship with symptomatic apical periodontitis. A systematic review and metaanalysis", Int Endod J, 49 (3), pp.255-70. 